\title{
THE (UN)REASONABLENESS OF RAWLSIAN RATIONALITY
}

\author{
Shaun Young \\ Department of Political Science \\ York University*
}

ABSTRACT: In Political Liberalism John Rawls argues that "the reasonable" and "the rational" are "two distinct and independent" ideas. This differentiation is essential to the viability of Rawls' conception of political liberalism insofar as it facilitates the recognition and subsequent voluntary acceptance of the need for a public conception of justice that requires all individuals to forsake the unfettered pursuit of their personal ambitions. However, the soundness of Rawls' argument is premised upon a number of questionable claims that, in effect, render his proposed distinction between the reasonable and the rational more chimerical than real, and in so doing critically undermine the ability of his conception of justice to secure the type of voluntary public consensus he deems necessary to establish and sustain a just and stable liberal democracy. It is concluded that the only way one can be assured of generating the sought after conditions is to develop a regulatory framework that publicly supports and protects the principles embodied in Rawls' conception of reasonableness, rather than relying upon the reasonableness of individuals to secure and nourish the required conditions.

In Political Liberalism John Rawls (1993: 51) argues that "the reasonable" and "the rational" are "two distinct and independent" ideas. This differentiation is critical to the viability of his conception of political liberalism: It allows him to claim that individuals can effectively distinguish between what is "reasonable" and what is "rational," which, in turn, enables them to recognize the value and, indeed, necessity of adopting and supporting a public conception of justice ${ }^{1}$ that requires all individuals to forsake the unfettered pursuit of their personal ambitions. Given the ineliminable diversity of reasonable moral, religious, and philosophical beliefs that characterizes contemporary liberal democracies - that is, the fact of reasonable pluralism-such recognition is essential if Rawlsian political liberalism is to provide for the establishment and preservation of the sociopolitical conditions necessary to secure and sustain a just and stable (in Rawlsian terms, well-ordered) liberal polity.

However, the viability of Rawls' argument is premised upon a number of questionable claims that, in effect, render his proposed distinction between the reasonable and the rational more chimerical than real. In particular, when one penetrates the surface of Rawls' argument, it becomes clear that in a society governed by the principles of Rawlsian political liberalism a person's goals and related behavior can be considered genuinely rational only to the extent that they qualify as reasonable. If, as Rawls contends, a person's public behavior must be reasonable if it is to be legitimately accommodated, protected, and facilitated, then maximizing one's potential to achieve her

\footnotetext{
* The author is currently a Social Sciences and Humanities Research Council of Canada postdoctoral fellow in the Department of Political Science at York University, Toronto, Canada. This essay is not for quotation or citation without permission of the author; comments are welcomed (spyoung@yorku.ca; shaun.young@flinders.edu.au).
} 
personal ambitions - that is, acting in a "rational" manner-will require that she act "reasonably," as such is defined by the public conception of justice. Hence, the likelihood of success in realizing one's personal goals will be a measure of their reasonableness. In essence, then, one must act reasonably to act rationally. If such is the case, it becomes extremely difficult to argue persuasively that the reasonable and the rational are "two distinct and independent" ideas in any meaningful practical sense. Contra Rawls (1993: 339), his conception of reasonableness does not merely "frame" and "subordinate" rationality; rather, it orders and animates its very being. This fact has important consequences for the viability of Rawls' argument, especially insofar as it renders his conception of public reasonableness unreasonably coercive and thereby undermines the ability of his proposed governance framework ${ }^{2}$ to secure and sustain the type of widespread, voluntary overlapping consensus he deems essential to the establishment of a just and stable liberal polity.

In order to both justify my claim that Rawls' distinction between reasonableness and rationality is more illusionary than actual and support my related arguments concerning the "unreasonably" coercive character of Rawlsian reasonableness, it will first be necessary to recount his understanding of the proper character of reasonableness and rationality and the relationship between the two. Only after having done so will it be possible to explain effectively in what sense and why his proposed distinction cannot be maintained in the manner required by his conception. ${ }^{3}$ Accordingly, I shall begin by providing both a brief description of Rawls' understanding of the distinction between reasonableness and rationality and a review of his related propositions, and then proceed to analyze their validity.

\section{Rawlsian Reasonableness and Rationality}

Rawls (1993: 50-51) identifies "reasonable" citizens as those who "seek a social world in which they, as free and equal, can cooperate with others on terms all can accept.” More specifically,

Citizens are reasonable when, viewing one another as free and equal in a system of social cooperation over generations, they are prepared to offer one another fair terms of social cooperation (defined by principles and ideals) and they agree to act on those terms, even at the cost of their own interests in particular situations, provided that others also accept those terms (Rawls, 1996: xliv).

Reasonable citizens will understand that the achievement of the social world they seek requires that they treat their fellow citizens in a "reasonable" manner, which necessitates that they recognize them as free and equal agents and "take into account the consequences of their actions on others' well-being” (Rawls, 1996: 49n1).

Reasonable citizens will, subsequently, "recognize" that reasonableness must be the "final court of appeal" in relation to decisions concerning conflict(s) between competing values and goals: indeed, it must be the standard used to judge the validity of all "public" claims - that is, claims that place demands upon all citizens of the polity. Only by assigning primacy to reasonableness, as opposed to a single understanding of the "truth," can one exhibit the requisite degree of respect for her fellow citizens. To employ a different standard 
would be to disrespect and degrade others' beliefs, and thereby effectively preclude the achievement of a society in which all citizens are able to "cooperate with others on terms all can accept” - the foundation of a just and stable (well-ordered) liberal polity.

It is important to note that in assigning primacy to reasonableness, citizens are not espousing an indifference or skepticism toward the truth of moral judgements; rather, they are acknowledging the importance of such matters but realize that 1) "while people can recognize everyone else's comprehensive views as reasonable, they cannot recognize them all as true"; 2) "there is no shared public basis to distinguish the true beliefs from the false"; and 3) it is impossible to obtain a "public" (which is to say, consensual) solution for such questions (Rawls, 1993: 128): "Certain truths, it may be said, concern things so important that differences about them have to be fought out, even should this mean civil war" (Rawls, 1993: 151-52). Recognizing these facts, "reasonable" citizens voluntarily refrain from publicly passing judgement as to the truth or falsity of moral claims in order to avoid such conflict and provide the foundation for an overlapping consensus. Such an approach is not, Rawls emphasizes, akin to showing indifference or skepticism toward the truth of moral judgements.

The "rational," Rawls (1996: 50) argues, refers to "a single, unified agent (either an individual or corporate person)," and concerns how the ends and interests of that agent are adopted and affirmed, how they are given priority, and the choice of means used to pursue them. In the case of the latter, the rational is guided by familiar principles such as "adopt[ing] the most effective means to ends, or ... select[ing] the more probable alternative, other things equal” (Rawls, 1996: 50). In essence, people act rationally when they use their "powers of judgment and deliberation in seeking ends and interests peculiarly ... [their] own" (Rawls, 1993: 50) - ie when they develop and pursue a particular conception of the good intelligently. ${ }^{4}$ Importantly, according to Rawls (1996: 51; see also 56), rational agents need not be limited to means-end reasoning: "they may balance final ends by their significance for their plan of life as a whole, and by how well these ends cohere with and complement one another." Nor need it always be the case that rational agents act solely in a self-interested manner; they may pursue interests the realization of which are of benefit not to themselves but to others-for example, relatives, friends, community, country. (Rawls, 1996: 51). Indeed, Rawls (1996: 51) contends that "[r]ational agents approach being psychopathic when their interests are solely in benefits to themselves."

In summary-and more simplistically—for Rawls, the capacity to be reasonable is the capacity for a sense of justice, and the capacity to be rational is the capacity to form and pursue a conception of the good intelligently (Rawls, 1996: 81). Rawls (1993: 51) insists that "the reasonable and the rational are two distinct and independent ... ideas," at least insofar as "there is no thought of deriving one from the other." In particular, he (1996: 49n1) emphasizes that "[t]he disposition to be reasonable is neither derived from nor opposed to the rational but it is incompatible with egoism.” Having declared their difference, Rawls further adds that, "within the idea of fair cooperation"-an essential component of his conception - the reasonable and the rational are complementary and interdependent ideas. They are complementary in that they work together to specify the terms of fair cooperation; they are interdependent insofar as neither "can stand without the other" (Rawls, 1996: 52): "Merely reasonable agents would have no ends of their own they wanted to advance by fair 
cooperation; merely rational agents lack a sense of justice and fail to recognize the independent validity of the claims of others" ${ }^{25}$ (Rawls, 1996: 52).

However, though Rawls suggests that reasonableness and rationality are complementary and interdependent ideas, it is reasonableness that reigns supreme in his conception and its supporting arguments. ${ }^{6}$ Political Liberalism (and, for that matter, much of the work that preceded it) is rife with references to the reasonable, reasonableness, and a host of other terms that use the word "reasonable" as an adjective. More importantly, the tangible significance of reasonableness is evident even when such terms are absent. The importance of reasonableness for Rawlsian political liberalism is perhaps best exemplified by the fact that reasonableness, not truth, is the ultimate standard against which citizens of a Rawlsian polity must judge the acceptability and legitimacy of the public conception of justice and all political claims and decisions. Indeed, Rawls is extremely careful to ensure that he presents his conception of justice ${ }^{7}$ as one that claims only to be reasonable, as opposed to true. ${ }^{8}$ Not surprisingly, this fact has an inescapable influence on the entirety of Rawls' project, and its consequences are significant and manifest themselves in a number of ways.

For example: the conception of justice that lies at the heart of Rawls' paradigm is concerned almost solely with those individuals who affirm "reasonable" comprehensive doctrines. According to Rawls (1993: 36-37), reasonable comprehensive doctrines are "the doctrines that reasonable citizens affirm and that political liberalism must address. They are not [as is presumably the case with unreasonable comprehensive doctrines] simply the upshot of self- and class interests, or of peoples' understandable tendency to view the political world from a limited standpoint." "Unreasonable" comprehensive doctrines and their supporters are of concern only to the extent that both must be effectively managed to avoid their generating political instability (for example, Rawls, 1996: 64n19).

Also inherent in Rawls' notion of a purely political liberalism is the expectation that the majority of citizens will faithfully act in a "reasonable" manner. Only by fulfilling such an expectation is it possible to secure the conditions that will enable the establishment and preservation of a just and stable liberal polity. Satisfying such a caveat necessarily requires that individuals be able to differentiate between reasonable and unreasonable demands and somehow guarantee that decisions related to questions of political justicequestions concerning constitutional essentials and matters of basic justice such as "who has the right to vote, or what religions are to be tolerated, or who is to be assured fair equality of opportunity, or to hold property" (Rawls, 1993: 214) ${ }^{9}$-are justified by reference to only those demands that all "reasonable" individuals can "reasonably" be expected to support voluntarily. Failure to secure such a differentiation or surety will effectively preclude the possibility of adequately insulating the political from the nonpolitical and thereby prevent the development of a conception of justice that can offer the basis for a public agreement able to achieve the degree of stability required to establish and sustain a well-ordered liberal democracy.

In essence, Rawlsian political liberalism is concerned to provide a public conception of justice that can accommodate the demands of reasonable comprehensive doctrines and reasonable citizens situated in an environment of reasonable pluralism. Arguably, only by adopting such a "focused," idealized approach can Rawls hope to offer a framework 
capable of achieving the type of overlapping consensus he seeks, and thereby secure the sociopolitical conditions essential to the achievement of a just and stable liberal polity.

\section{Being Reasonably Rational}

As the above review suggests, the viability of Rawls' conception is dependent upon both the presence of reasonableness and its ability to regulate behavior effectively. Rawlsian political liberalism can achieve its stated goal-to provide the framework for the establishment and preservation of a just and stable liberal democracy—only if individuals are effectively able and willing to separate the reasonable from the rational and assign primacy to concerns of the former when making decisions regarding what they can "reasonably" demand of their fellow citizens, especially those with whom they disagree respecting the proper features of the "good" life. Only by ensuring such behavior is it possible to obtain the type of reciprocal respect and accommodation needed to secure the overlapping consensus sought by Rawls.

Rational citizens in a polity guided by the principles of Rawlsian political liberalism are expected (indeed, required) to recognize that, given the ineliminable diversity of competing, antagonistic and often irreconcilable views that will invariably exist in contemporary liberal democracies, establishing and sustaining the conditions that will enable all reasonable individuals to pursue and (hopefully) realize their chosen ends is dependent upon securing certain safeguards for all citizens. In particular, citizens must be assured the freedom to affirm and publicly pursue a life-plan of their own choosing (and, should it be the case, of their own design); this caveat necessitates that individuals "reasonably" temper the demands that they place on their fellow citizens. More specifically, one cannot expect others voluntarily to accept and support the pursuit of a personal goal if either the pursuit or realization of the goal would negatively impact upon the ability of one's fellow citizens to pursue or realize their own "reasonable" ambitions. Rational citizens will understand that only by supporting a public conception of justice that secures the necessary safeguards can they hope to establish an environment of reciprocal respect for one another's "particular ends and interests," and thereby generate the conditions that will allow all "reasonable" individuals to pursue freely and (hopefully) achieve their respective "rational” goals.

Beyond the public provision of certain fundamental safeguards, Rawls (1993: 189) places the onus on the individual by suggesting that citizens should voluntarily and of their own initiative adopt goals that adequately reflect "the all-purpose means they can expect, given their present and foreseeable situation." If individuals choose "unreasonable" goals and, subsequently, lack the "means" needed to realize their chosen goals, then it is their responsibility to adjust their preferences to better correspond to "the all-purpose means" they can expect; the public conception of justice is not unfair or unjust merely because individuals fail to attain unrealistic goals. Consequently, if one hopes to achieve her goals without having to rely upon unacceptable or illegitimate force to do so, then she must pursue only "reasonable" objectives-goals the pursuit of which all "reasonable" people can "reasonably" be expected to accept voluntarily. The opportunity to realize one's "rational" ambitions will therefore be overwhelmingly determined by the degree to which said ambitions can be considered "reasonable.” It thus 
becomes "rational" for individuals to allow their understanding of rationality to be regulated by the public conception of reasonableness; indeed, such subjugation is essential if one hopes to maximize her chances of realizing her vision of the good life.

However, such a condition has the practical effect of making it impossible to act rationally without acting reasonably. Arguably, then, in a very important sense the rational is derived from the reasonable. To the degree that such a conclusion is valid, it undermines the viability of Rawls' conception. In particular, if the above description of the relationship between the reasonable and the rational is accurate, then the ability of Rawls' conception to serve as the basis for the type of overlapping consensus he envisions and requires is critically impeded. Prior to further developing this argument, it will be useful to address a likely criticism of the claim that the rational is derived from the reasonable.

It might be complained that the above commentary reveals only what Rawls (1993: 339) willingly concedes: namely, that "the reasonable frames and subordinates the rational." Hence, noting that citizens' rational pursuits must respect the demands of public reasonableness is neither a particularly insightful observation nor an especially meaningful criticism. However, Rawls' representation of the regulative authority possessed by the public conception of reasonableness problematically understates (or underestimates) both the coercive power it does—and must—wield and the resulting difficulties that such coercion generates for efforts to distinguish between the reasonable and the rational. If "rational" behavior must respond to the demands of public reasonableness in the sense described above, then it becomes extremely difficult (if not impossible) to argue credibly that, in practice, the rational maintains any meaningful degree of independence from the reasonable. In the final analysis, the regulatory authority exercised by the public conception of reasonableness, combined with the (acknowledged) interdependency between the reasonable and the rational, make the practical effect of Rawls' distinction virtually meaningless.

In turn, if the rational cannot be meaningfully distinguished from the reasonable, then the viability of Rawls' conception becomes dependent upon those subject to its constraints voluntarily and faithfully ensuring that their goals and related behavior adhere to the requirements of the public conception of reasonableness. According to Rawls, generally speaking, the citizens inhabiting existing liberal democracies already more than sufficiently exhibit such a willingness and fidelity; this belief, Rawls (for example, 1993: $13,15,54,167)$ contends, is not merely hopeful conjecture on his part: it is, rather, grounded in empirical fact. Such being the case, it is neither unrealistic nor improbable to suggest that in instances of potentially divisive, destabilizing conflict between the rational and the reasonable, individuals will voluntarily be willing to assign primacy to the latter.

However, as George Klosko (for example, 2000) has noted, the accuracy of Rawls' "empirical" claims is, at minimum, extremely suspect. According to Klosko, a significant volume of social science research concerning the attitudes of citizens in a number of contemporary constitutional democracies critically undermines the validity of Rawls' belief in the "reasonableness" of said citizens. In particular, citizens' willingness to respect the beliefs of others "reasonably" and voluntarily seems to be much less assured than Rawls suggests. Various studies conducted during the preceding fifty years 
reveal that when push comes to shove, many individuals are publicly willing to declare certain seemingly "reasonable" views (as such are defined by Rawls) to be unacceptable and demand actions which abridge many of the "basic liberties" promoted by Rawlsian political liberalism (Klosko, 1993: 352; see also Klosko, 2000: 42-115). Indeed, it has been calculated that somewhere between 20 percent and 40 percent of the U.S. population, for example, affirms doctrines that would be incompatible with the demands of Rawls' conception (Klosko, 1996: 258-59; see also Klosko 2000). (It is worth noting that 20 percent of the population of the United States translates into approximately 50 million people.) Further, it has been argued (Klosko, 1996: 258-59; see also Klosko 2000) that while anywhere from 60 percent to 80 percent of the U.S. population affirms what could be labeled "moderate" doctrines - that is, doctrines which do not generate "unbridgeable gaps" among the citizenry—when trying to resolve contentious political questions, the general ignorance of the members of this cohort "allows extremists and special interest groups to play on their emotions and so to manipulate them" (Klosko, 1996: 259), thereby enabling (purportedly) "rational" but "unreasonable" objectives to win the day.

If it is unrealistic not to expect a significant percentage of the citizenry to be unable or unwilling to adhere to the demands of public reasonableness voluntarily and faithfully, then Rawlsian political liberalism cannot "reasonably" be expected to secure the type of "substantial" overlapping consensus it seeks (Rawls, 1993: 38). Hence, the failure of Rawls to provide for a meaningful distinction between the reasonable and the rational imposes a requirement- that all citizens freely, willingly and reliably defer to the requirements of the reasonable in instances of conflict between the reasonable and the rational - that critically hampers the ability of his conception to secure the public support and subsequent political stability needed to establish and sustain a just and stable liberal democracy, the raison d'être of Rawls' conception.

\section{Separating the Public from the Nonpublic}

It might be objected that the foregoing analysis overlooks an important fact: namely, that Rawls separates the public from the nonpublic, ${ }^{10}$ and this separation significantly undermines the claim that the public conception of reasonableness exhibits a problematic coerciveness or demands an "unreasonable" homogeneity of beliefs. To explain: Rawls explicitly states that it is only citizens' "political" goals and behavior - those pursuits that place demands upon all citizens of the polity - that need be constrained by the public conception of reasonableness. It is both suggested and assumed that there will be a large sphere of nonpublic activity that remains free from the restrictions imposed on one's public pursuits by the public conception of reasonableness. For example, followers of the Roman Catholic religion are free to embrace and publicly promote membership in a religious community that prohibits females from becoming members of its clergy, despite the fact that the inequality generated by such a prohibition would be deemed publicly "unreasonable" and, subsequently, unacceptable were one to demand that a similar restriction be applied to political offices of the state. The point is that within the nonpublic sphere, citizens' "rational" pursuits need not be (problematically) impeded by the requirements of public reasonableness. Indeed, in the nonpublic sphere, citizens can 
pursue a variety of publicly "unreasonable" goals. Hence, though certain goals and behavior must respect the demands of public reasonableness, Rawls' separation of the public and the nonpublic ensures a significant (and sufficient) opportunity for citizens to pursue important personal goals free from such constraints. Thus in a very valuable sense rationality neither collapses into reasonableness nor does it become its prisoner.

The most obvious and elemental problem with such an argument is that its viability relies upon the ability of individuals to separate clearly the public from the nonpublic. Rawls believes that all (reasonable?) individuals possess such a capacity. According to Rawls (1993: 38, 140), each citizen's “overall view” consists of two distinct yet related views: "one ... can be seen to be, or to coincide with, the publicly recognized political conception of justice; the other ... is a (fully or partially) comprehensive doctrine to which the political conception is in some manner related." Such cognitive schizophrenia makes it possible for individuals to distinguish the public from the nonpublic. In turn, because reasonable individuals understand that the achievement of the social world they seek requires that they treat their fellow citizens in a "reasonable" manner, they will voluntarily be willing to assign primacy to "public" concerns when such concerns conflict with their nonpublic ambitions.

However, surely a person's idea of the good (which is to say, the rational) will fundamentally and inextricably influence her understanding of precisely what constitutes a "reasonable" public demand. For example, someone who believes that the sanctity of life is inviolable, and further believes that life begins at the moment of conception, could not willingly support a public model of reasonableness that allows a fetus to be purposely aborted at any stage of a woman's pregnancy, despite the fact that any related law would not prevent that person from refusing to ever undergo or otherwise directly participate in an abortion. Similarly, if I believe that the only legitimate and acceptable form of marriage is that between a man and a woman, then I am not likely to accept voluntarily any public conception of reasonableness that permits same-sex marriage, regardless of the fact that merely allowing such an alternative does not require that I accept it within the scope of my "nonpublic" life. As Rawls (1996: 58) seems to concede, such "prejudice and bias, self- and group interest, blindness and willfulness" cannot be isolated from public/political life.

The point is this: from the perspective of their supporters, certain important (seemingly) "nonpublic" beliefs and values need to be publicly recognized and protected if they are to be effectively accommodated and the public conception of justice is to provide for the "reasonable" pursuit and realization of associated "rational" conceptions of the good. Even if it does not require the "nonpublic" acceptance of "offensive" beliefs and behavior, any public conception of reasonableness that allows for their accommodation will, nevertheless, be considered unacceptable. Unfortunately for Rawls, far from supporting or even desiring the separation of public reasonableness from nonpublic reasonableness, individuals seem increasingly willing to demand that nonpublic beliefs and values - those that are unable to secure a free and willing consensus among the adherents of a diversity of competing irreconcilable doctrines-be publicly accommodated and reflected in governmental policies and practices. With greater frequency individuals are demanding that governments take a "moral" stand on the (un)acceptability of certain activities and practices (for example, abortion, euthanasia, 
same-sex marriage, stem-cell research, etc), regardless of whether the legal requirements of such a stand violate existing judicial interpretations of certain constitutional principles. The emergence and acceptance of concepts such as the "politics of difference" and the "politics of identity" have further blurred the distinction between the public/political and the nonpublic/nonpolitical; for many, now more so than ever before, "the personal (nonpublic) is the political (public)," and the rational, like the reasonable, "addresses the public world of others" (Rawls, 1996: 62). Hence, though there might be certain "nonpublic" matters that individuals could effectively isolate from the public realm, there is likely to be an equal or greater number for which such isolation would be considered undesirable, "unreasonable" or impossible.

Perhaps most importantly, even if one accepts Rawls' optimistic portrayal of individuals' ability to separate the public from the nonpublic, the latter can never entirely escape the constraints of the former, especially insofar as there always remains an overarching prohibition against nonpublic behavior forcibly violating the principles of public reasonableness - that is, any of the basic rights and liberties provided by the political conception of justice. Arguably, then, though the theoretical distinction made by Rawls seems relatively simple and clear, in practice such a distinction cannot be effectively maintained and is thus untenable. However, if the distinction between the public and the nonpublic cannot be effectively maintained, then, by extension, neither can the separation of the reasonable from the rational. Rawls (1996: 54) concedes as much when he states: "Without an established public world, the reasonable may be suspended and we may be left largely with the rational.” And, as previously noted, an inability to maintain a meaningful separation of the reasonable from the rational prevents Rawls' conception from securing the type of voluntary, widespread public support he believes is needed to establish and sustain a just and stable liberal polity.

Furthermore, merely being able to separate the reasonable from the rational does not eliminate all potential significant problems. In particular, in order to ensure that all rational pursuits are appropriately tempered by reasonableness, all citizens must, among other things, voluntarily affirm the same understanding of reasonableness. However, as Rawls (for example, 1996: 58) seems to acknowledge, different "reasonable" individuals will affirm different understandings of what constitutes a "reasonable" demand. Indeed, the specific characteristics and demands of "reasonableness" will inevitably be a source of debate and disagreement among citizens, especially in contemporary liberal societies (see, for example, Bohman 1995; Klosko 2000; Neal 1995; and Young 2001). At minimum, "there are, have been, and will be many people (millions and millions!) who are at least as reasonable as John Rawls and ... who do not believe in the values of political liberalism or the liberal version of tolerance" (Neal 1995). Yet, widespread agreement on a "thick" definition of what constitutes a reasonable demand is necessary for the establishment and maintenance of a reliable overlapping consensus.

Moreover, even if the requisite number of citizens already were or became reasonable in the necessary sense, there could be no guarantee that they would always remain so. Reasonableness is a fluid and contested concept, and it is too dynamic and fickle a basis upon which to premise citizens' continued support for the prevailing public definition of "reasonable." If reasonableness is to provide the basis for a stable overlapping consensus, then all reasonable citizens must not only affirm, but also 
maintain, the same definition of "reasonable" — specifically, that propounded by Rawls. Only by ensuring such an enduring homogeneity can one be assured of securing the type of unwavering public support required to guarantee the continuation of an overlapping consensus. However, given the unavoidable heterogeneity and fluidity of reasonableness, it seems improbable and, indeed, implausible to suggest that all (or even the majority of) people will voluntarily endorse and remain faithful to any single definition of "reasonable" and its associated demands. Subsequently, by itself, citizens' willingness to assign primacy to reasonableness when confronted with a conflict between the reasonable and the rational does not resolve all significant problems.

In the final analysis, Rawls' proposed distinction between the public and the nonpublic is unable to seriously undermine the claim that the viability of his conception is dependent upon the exercise of an "unreasonable" degree of coerciveness on the part of the public conception of reasonableness. In turn, the exercise of such coercion critically diminishes the ability of Rawls' conception to achieve the type of overlapping consensus that he deems necessary for the establishment and preservation of a well-ordered liberal polity.

\section{Conclusion}

Despite Rawls' claim to the contrary, his conception of the reasonable is not merely an interdependent and complementary idea of the rational; nor does it serve only to "frame" and "subordinate" the rational. Rather, Rawlsian reasonableness orders and animates the rational; it serves as a Hobbesian-style sovereign in Rawls' conception, effectively rendering rationality its prisoner. In doing so, it premises the viability of Rawls' conception upon the willingness of individuals to voluntarily and faithfully ensure that their goals and related behavior adhere to the requirements of the public conception of reasonableness. However, for a number of reasons, the satisfaction of such a condition is unrealistic to expect and impossible to guarantee; in particular, it requires a homogeneity and continuity of belief that cannot reasonably be expected in contemporary liberal democracies. Consequently, the degree of coercive authority that Rawls' conception of reasonableness must exert to secure the required behavior impedes individual freedom in a manner that critically undermines the ability of his proposed governance framework to provide the flexibility and accommodation required to secure the free and willing support of a "substantial" majority of the citizens of contemporary liberal democracies-a condition that must be fulfilled if Rawlsian political liberalism is to secure the sought after political stability (Rawls, 1993: 38). ${ }^{11}$ Rawls' proposed distinction between the public and the nonpublic and the related stipulation that only public behavior need be constrained by the public conception of reasonableness is unable to ensure any meaningful independence for rationality, and, subsequently, fails to mitigate the constraining effect of the public conception of reasonableness, thus leaving Rawls' governance framework unable to secure the type of overlapping consensus he believes is necessary to establish and sustain a just and stable liberal democracy.

Perhaps somewhat paradoxically, it would seem that the only way one can be (relatively) assured of establishing and sustaining the conditions needed to achieve the political stability sought by Rawls is to develop a conception of justice that publicly 
supports and protects the principles in question, rather than relying upon the reasonableness of individuals to secure and nourish the required conditions. A cursory review of contemporary history reveals the potentially horrific consequences associated with merely presuming that the majority of citizens will reliably act in a "reasonable" manner - that is, freely and willingly subordinate their fundamental aspirations to the demands of public reasonableness in order to obtain and maintain a "just" sociopolitical environment. If we are to avoid the dangers associated with such an expectation, we must be more proactive in terms of ensuring adherence to certain values and safeguarding their primacy in the public realm.

Accordingly, what is needed is a public conception of justice that forcefully supports and protects the liberal values embodied in Rawls' notion of reasonableness. If it is true that there is "no social world without loss" (Rawls, 1993: 197n32), ${ }^{12}$ and if it is also true that many of the citizens of contemporary liberal democracies already support the values embraced by Rawlsian political liberalism (for example, Rawls, 1993: 13, 15, 167), then taking the additional step of publicly and actively endorsing and protecting such values should not constitute an unacceptably onerous or offensive imposition on those concerned. The only notable difference between such an approach and that advocated by Rawls is that the former is willing to declare publicly the value of what the latter requires to achieve its goals but is explicitly unwilling to demand of its adherents. It is in this respect that Rawlsian political liberalism falters by forsaking practicality for philosophical continuity. Though Rawls' conception appears to embrace the concerns of both philosophical liberalism and empirical practicality, it, nevertheless, fails to achieve a realistic balance between the two. Such a balance requires that the frailties of human nature-unreasonableness, irrationality, egoism, etc — not only be adequately recognized, but also effectively protected against.

The operationalization of such an approach would seem to require that the liberal belief in the justness of the principles of toleration and equal respect explicitly guide all public policy and, subsequently, the activities of all public institutions, including the public education system. If the goal is to establish and preserve a sociopolitical environment that offers the greatest opportunity for each citizen to pursue her freely chosen vision of the good life and thereby (hopefully) realize self-fulfilment, then a regulatory framework that unequivocally demands that primacy be given to the principles of toleration and equal respect would seem to offer the best possible option. Given that the boundaries of accommodation must be drawn somewhere, such an approach not only secures the greatest practical degree of accommodation, it also provides the most effective means for its protection by explicitly requiring that public behaviour, both on the part of individuals and government, adhere to the demands of toleration and equal respect, thereby significantly reducing the need to rely upon human reasonableness to achieve the desired results.

Though the resulting regulatory framework transgresses the boundaries of neutrality advocated by Rawls, and insofar as it does is more "perfectionist" in character, arguably, it is no more illiberal or exclusionary in its practical effect than is the framework produced by his conception. Hence, the proposed alternative approach offers a paradigm that is able to provide greater certainty with respect to generating and sustaining the type of public behaviour necessary to secure and preserve the sought after sociopolitical conditions, while maintaining an actual degree of accommodation equal to that available from Rawlsian political liberalism. Both in terms of its practical consequences and its fundamental 
character, then, the proposed alternative does not represent a significant departure from the approach promoted by Rawls. However, insofar as the above recommended approach more fully acknowledges and responds to the frailties of human nature and in so doing secures greater protection against unreasonable public behaviour, it presents a more practical and, by extension, useful response to the problem of political stability than does that offered by Rawls conception. 


\section{Notes}

${ }^{1}$ As does Rawls (for example, 1985, 1993), I will use the terms "public” and "political” interchangeably.

${ }^{2}$ By “governance framework” I mean Rawls’ political conception of justice.

${ }^{3}$ Unless specified otherwise, all references to Rawls' “conception” refer to his conception of political liberalism.

${ }^{4}$ The term intelligently has been italicized to emphasize that one acts rationally not merely by pursuing her particular ends and interests, but by doing so in an intelligent manner. As Rawls (1996: 49n1) notes: "knowing that people are rational we do not know the ends they will pursue, only that they will pursue them intelligently."

${ }^{5}$ More specifically, "rational agents lack ... the particular form of moral sensibility that underlies the desire to engage in fair cooperation as such, and to do so on terms that others as equals might reasonably be expected to endorse" (Rawls, 1996: 51, see also 51n3).

${ }^{6}$ There are a number of (relatively) recently published articles the conclusions of which support this claim. See, for example, Michael DePaul (1998); Kai Nielsen (1998); Jon Mandle (1999); and Shaun Young (2001).

${ }^{7}$ Unless specified otherwise, all references to the "conception of justice" should be understood as referring to the political/public conception of justice.

${ }^{8}$ This fact is emphasized (in different ways) throughout the entirety of the text. For a specific statement to this effect see Rawls (1993: xx).

${ }^{9}$ For a more detailed account of exactly what type of issues are considered "constitutional essentials and matters of basic justice,” see Rawls (1993: 227-30).

${ }^{10}$ It should be noted that the dichotomy between the public and the nonpublic is synonymous with the distinction between the political and the nonpolitical. Further, the nonpublic/nonpolitical is, in effect, Rawls' manner of categorizing what others commonly refer to as the personal or the private.

${ }^{11}$ Though Rawls (for example, 1993: 38) does, in places, add the qualification "politically active citizens," he fails to elaborate as to what exactly constitutes a "politically active" citizen. Furthermore, I believe that my omission of this qualification is justified by Rawls' use (for example, 1993: xvi) of other less specific statements. For an interpretation that supports this argument, see Klosko (1993: 349, 350).

12 Paraphrasing Isaiah Berlin, Rawls (1993: 197n32; see also 57) notes that "there is no social world without loss: that is, no social world that does not exclude some ways of life that realize in special ways certain fundamental values." 


\section{References}

Bohman, James. 1995. "Public Reason and Cultural Pluralism: Political Liberalism and the Problem of Moral Conflict.” Political Theory 23: 253-79.

DePaul, Michael. 1998. “Liberal Exclusions and Foundationalism.” Ethical Theory and Moral Practice 1: 103-20.

Klosko, George. 1993. "Rawls's 'Political' Philosophy and American Democracy." American Political Science Review 87: 348-59.

Klosko, George. 1996. “Liberalism and Pluralism.” Social Theory and Practice 22: 25169.

Klosko, George. 2000. Democratic Procedures and Liberal Consensus. Oxford University Press: Oxford.

Mandle, Jon. 1999. “The Reasonable in Justice as Fairness.” Canadian Journal of Philosophy 29: 75-107.

Neal, Patrick. 1995. “Against Liberal Public Reason.” Paper presented at the Annual General Meeting of the Canadian Political Science Association. Unpublished.

Nielsen, Kai. 1998. "Liberal Reasonability as a Critical Tool? Reflections after Rawls." Dialogue 37: 739-59.

Rawls, John. 1985. “Justice as Fairness: Political not Metaphysical.” Philosophy and Public Affairs 14: 223-251.

Rawls, John. 1993. Political Liberalism. Columbia University Press: New York.

Rawls, John. 1996. Political Liberalism, paperback edition. Columbia University Press: New York.

Young, Shaun. 2001. "Divide and Conquer: Separating the Reasonable from the Unreasonable.” Journal of Social Philosophy 32: 53-69. 